\title{
Enhancement of performance in the Hebb-Williams maze by magnesium pemoline'
}

\author{
JOEL F. LUBAR, JOHN J. BOITANO, EOWARD M. GUROWITZ AND BRENT R. AIN
}

UNIVERSITY OF ROCHESTER

Magnesium pemoline, a central nervous stimulant implicated in brain RNA production, decreases both time and errors in the Hebb-Williams maze, a test of animal intelligence. The effect of the drug on errors is confounded with its effect on time, but seems to have a component independent of the latter effect.

Recent experiments have reported contradictory effects of injections of RNA on learning and memory (Cameron \& Solyom, 1961; Cook et al, 1963; Ison \& Taplin, 1966; Corson \& Enesco, 1966; Luttges et al, 1966; Wagner et al, 1966). In tasks employing shockmotivated behavior as the index of performance, the beneficial effects of exogenous RNA may possibly be due to a hyperreactivity to the nociceptive stimulus (Wagner et al, 1966). Thus, it would seem desirable to employ a shock-free behavioral task and a compound which catalyzes the production of intracellular brain RNA.

Glasky \& Simon (1966) have shown that magnesium pemoline, a mild central nervous system stimulant, does indeed augment RNA polymerase which, in turn, facilitates the production of endogenous RNA. Plotnikoff (1966) has reported facilitatory effects of magnesium pemoline in rats on the acquisition and retention of a "jump-out" avoidance response.

In a maze situation specifically designed as a rodent "'intelligence test"' (Hebb \& Williams, 1946), Ison \& Taplin (1966) reported weak but nonetheless facilitatory effects of yeast RNA on performance as measured by error scores. The present experiment was designed to investigate the influence of magnesium pemoline on rats trained in the Hebb-Williams maze.

\section{Method}

The Ss were 18 male Holtzman, Sprague-Dawley rats. All the Ss were 70 days old at the start of the experiment, which lasted 24 days.

The apparatus employed was the Hebb-Williams maze, and was the same apparatus used by Ison \& Taplin (1966). The maze floor was divided by red lines into squares, with start and goal boxes placed at opposite corners of the maze.

Training consisted of two phases, designated adaptation and testing. During adaptation, all animals received daily intraperitoneal (IP) injections of $1 \mathrm{cc}$ of a $0.3 \%$ solution of gum tragacanth, which later served as the placebo injection and as the vehicle for suspension of the drug. For two periods of six days, each $S$ was given 10 massed daily trials on each of six different problems. These problems, while not part of the standard Hebb-Williams series, were designed to bring all the animals to a common level of familiarity with the experimental situation. Animals were maintained on $23 \mathrm{hr}$. of water deprivation, with food available ad libitum, and were run in the maze for a reward of $0.2 \mathrm{cc}$ of water.

Data were taken in the form of time and error scores on each trial. Time scores consisted of the time elapsed from leaving the start box to entering the goal box. Errors were designated as any movement away from the most direct path to the goal and any entry with two feet into designated "error squares."

At the conclusion of adaptation, an independent observer dichotomized the animals into matched groups on the basis of the rankings of both the time and error scores. Each $\mathbf{E}$ tested an approximately equal number of drug and placebo animals but was unaware of the group status of each S. All injections during testing were administered by an outside observer.

In the testing phase of the experiment, 12 problems, I-A to I-L in the Hebb-Williams (1946) series, were presented in alphabetical order, one problem per day as in adaptation. All $\mathrm{Ss}$ were injected $30 \mathrm{~min}$. before beginning testing, with each animal receiving IP approximately $1 \mathrm{cc}$ of solution, either the placebo solution described above, or a suspension containing $2.0 \mathrm{mg} / 100 \mathrm{gm}$ body weight of magnesium pemoline (Cylert, Abbott) suspended in the same gum tragacanth solution. Time and error scores were recorded after each trial.

Results

The maze data were analyzed in terms of both speed (reciprocal time) and error scores. Drug and placebo groups were found to be significantly different on both measures, both as a function of problems and of trials within problems (Table 1). That is, as shown in Fig. 1, drug animals were "better," i.e., showed lower time and error scores on some but not all problems (differences were on problems $D, F$, , $H, J$, and $K$ ), and, on a given problem, were better on some trials than on others. The interaction effects are not significant in this case (Table 1), so that drug

Table 1. Summary of Statistical Comparisons

\begin{tabular}{lccc}
\multicolumn{1}{c}{ Effect Tested } & \multicolumn{2}{c}{$\begin{array}{c}\text { Probability } \\
\text { Speed }\end{array}$} & Covariance \\
\hline Drug vs. Placebo & $<.05^{\star}$ & $<.05^{\star}$ & $n . s$. \\
Among Problems & $<.01$ & $<.01$ & $<.01$ \\
Among Trials & $<.01$ & $<.01$ & $<.01$ \\
Interactions: & & & \\
Drug x Problems & $<.01$ & n.s. & n.s. \\
Drug x Trials & n.s. & n.s. & n.s. \\
Drug x Problems x Trials & $\cdots$ & n.s. & $<.05$ \\
\hline
\end{tabular}

n.s. = not significant; * one-tailed hypothesis 

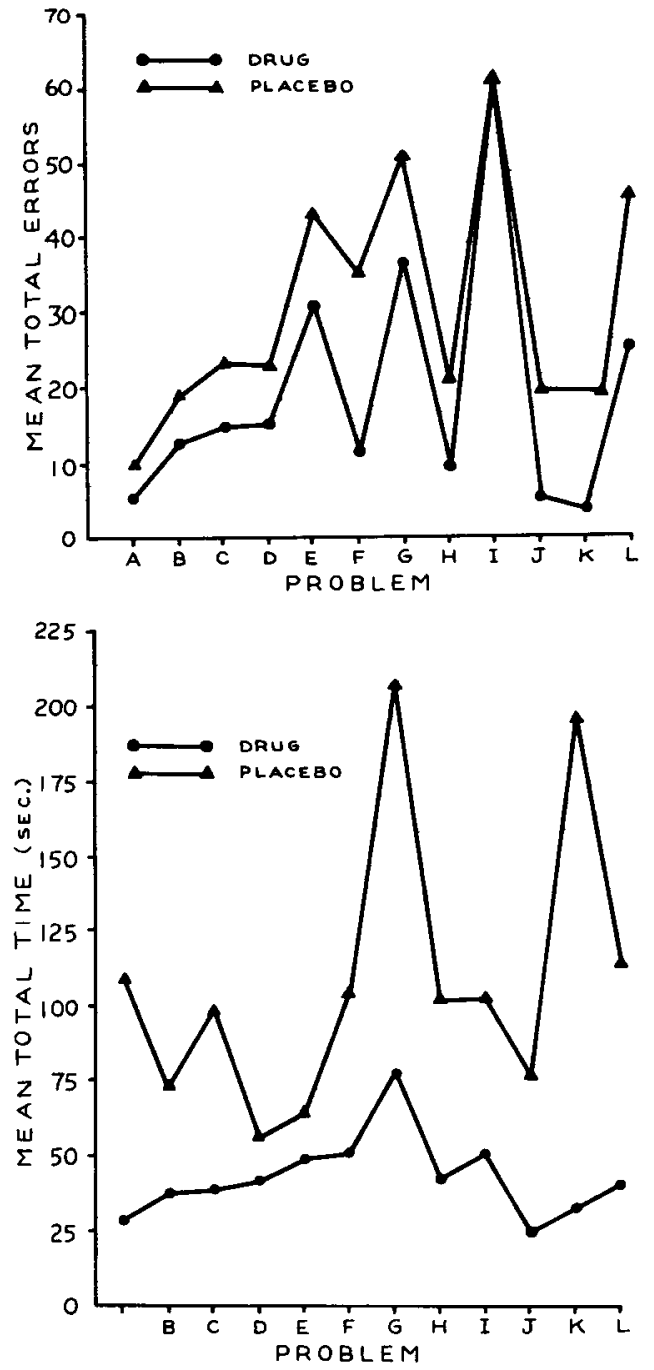

Fig. 1. Mean total errors per $S$ and mean running time in seconds for each $S$ on each maze problem

animals seem to run faster on all problems and on all trials, and again problems and trials are shown to differ within themselves. Further analyses indicated that the difference over trials was due to the drug animals' doing better only on early trials. Nevertheless, the drug animals were always better than the placebo animals.

Since time and errors were found to be significantly correlated $(r=.65$, Spearman $r h o, p<.01)$, it was felt that the effect of the drug on errors was confounded with its effect on time. To determine the extent of this confounding, an analysis of covariance was performed to adjust the error scores for the effect of the time scores. It was found that there was no significant main effect for the drug on errors alone, but instead a complex three-way interaction effect between the drug, problems, and trials, along with, as above, main effects for problems and trials. These results indicate that the component of the effect of the drug on errors which is independent of its effect on time is a complex one, which cannot be further delineated by the methods of this study.

\section{Discussien}

The results of this study suggest that magnesium pemoline has a facilitatory effect on performance in the Hebb-Williams situation. However, both this study and the previous report by Plotnikoff (1966) still leave unanswered the problem of whether magnesium pemoline enhances performance as a result of its stimulant effects or also affects learning and/or memory directly. Plotnikoff approached this problem by the use of sympathomimetic and nonsympathomimetic stimulants. It was shown that these control drugs were ineffective in altering either acquisition or retention of the tested avoidance responses, indicating that stimulation alone was not adequate for the effect he obtained.

The present study attacked the problem via a statistical approach, analysis of covariance, which was used to differentiate the facilitatory effect of magnesium pemoline on time scores from that on error scores. The results indicated that when this is one any residual effect of the drug on error scores is quite small.

While the question of how much of the effect of magnesium pemoline can be attributed to factors other than stimulation remains unresolved, the results of this study, taken together with those of Plotnikoff, indicate that magnesium pemoline does facilitate performance both for positive and negative reinforcement, and that in the latter case it does so where other known stimulants do not.

\section{References}

Cameron, D. E., \& Solyom, L. Effects of ribonucleic acid on memory. Geriatrics, 1961, 16, 74-81.

Cook, L., Davidson, A. N., Davis, D. J., Green, H., \& Fellows, E. J. Ribonucleic acid: Effect on conditioned behavior in rats. Science, 1963, 141, 268-269.

Corson, J. A., \& Enesco, H. E. Some effects of injections of ribonucleic acid. Psychon. Sci., 1966, 5, 217-218.

Glasky, A. J., \& Simon, L. N. Magnesium pemoline: Enhancement of brain RNA polymerases. Science, 1966, 151, 702-703.

Hebb, D. O., \& Williams, K. A method of rating animal intelligence. J. genet. Psychol., 1946, 34, 59-65.

Ison, J. R., \& Taplin, P. Reagent grade yeast RNA injections and rat performance in the Hebb-Williams maze. Psychon. Sci., 1966, 6, 495-496.

Luttges, J., Johnson, T., Buck, C., Holland, J., \& McGaugh, J. An examination of "transfer of learning" by nucleic acid. Science, $1966,151,834-837$.

Plotnikoff, N. Magnesium pemoline: Enhancement of learning and memory of a conditioned avoidance response. Science, 1966, 151, 703-704.

Wagner, A. R., Carder, J. B., \& Beatty, W. W. Yeast ribonucleic acid: Effects on learned behavior in the rat. Psychon. Sci., 1966, 4, 33-34.

\section{Note}

1. The authors gratefully acknowledge the assistance of the following: J. R. Ison and P. Taplin for the loan of apparatus and for suggestions; Susan Gern and David Wells for matching groups and injecting animals; Patricia Erdle for programming and data processing; Abbott Laboratories for their generous donation of the magnesium pemoline. 